or sigmoid gut can be made to reach the cæcum except by the aid of very violent massage.

Co-existence of Enterie Fever and Dysentery.-The co-existence of enteric fever with dysentery was more than once unexpectedly disclosed in our mortuary tent, and I am permitted to state that the medical returns of the hospital will show how very often the two diseases occur, if not simultaneously, within a short interval of one another. When coexistent the cardinal symptoms of either are certainly much modified, and it is in these cases especially that Widal's reaction has been of the greatest service to us.

\section{NOTES ON A CASE OF ACUTE YELLOW ATROPHY OF THE LIVER.}

BY G. H. PEARCE, L.R.C.P., L.R.C.S.EDIN., L.F.P.S.GLAS., Medical Officer and Public Vaccinator, Darton District Barnsley Union; Medical Officer of Health, Darton.

I HAVE been led to offer these few notes of an extremely interesting case, partly on account of its comparative rarity, the disease usually being seen in pregnant women, and also because it occurred in a man living under very healthy conditions, who spent a very active life, mostly in the fresh air. I saw him frequently before he was taken ill, the last time being a week before when he was out walking.

On the morning of June $16 \mathrm{th}$, 1900, I was sent for to see the patient, who was a farmer 33 years of age. His fa mily history was good, and as far as I could ascertain he had never had any illness with the exception of a cold occasionally. He informed me that his brother, two years younger, used to suffer from "the liver," but he had been all right for some years. The patient's wife told me that her husband had complained of feeling tired and exhausted for several days, and had frequently had to come in to rest whilst pursuing his ordinary avocation on his farm. Two days before calling me in he took to his bed, thinking he would be all right with day's rest, but getting worse they became alarmed, and decided to call in medical aid.

The temperature was $102^{\circ}$; the tongue was dry and baked, reminding one almost of the appearance in some cases of enteric fever; his eyes were glassy and his face slightly flushed; he complained of slight headache and sleeplessness he also said his throat felt sore. but on looking into it $I$ found very little to account for it. His pulse was 105, but of good tone. The heart was slightly displaced downwards and outwards, and there was a suspicion of a slight murmur at the apex. His lungs were congested at the bases, his respirations numbering 25 ; he bad no cough or expectoration. His abdomen was swollen and tympanitic. The area of hepatic dulness was almost entirely gone, and he had great pain on pressure over both the liver and spleen. The tenderness over the liver got better in two days, but worse over the spleen. He had not vomited, but the bowels had moved naturally. His water contained a trace of albumen, and was highly coloured we wished for no food, but was very thirsty. He complained of a good deal of pain in the muscles of his legs.

The next day he felt somewhat better, and his temperature and pulse were $100^{\circ}$ and 90 respectively; the respirations had also fallen to 20. He passed a fairly good day, but got restless towards night.

The next day he was much the same, but the temperature and pulse were lower.

On July 19th his pulse, temperature. and respirations were quite normal. He, however, could not rest anywhere in the bed, had had a sleepless night, and was slightly jaundiced; he had also vomited several times. His bowels had moved every day, but the motions had gradually got lighter in colour; his urine was also much darker and responded to the test for bile.

On June 2oth I was called at 7 A.M., and found him suffering from a violent hæmorrhage from the nose, which had only been going on for about twenty minutes, but during that time he had lost a great quantity of blood. His skin was intensely jaundiced, and numerous small hæmorrhages had occurred under the skin all over his body. He vomited several times during the day, but there was nothing special in its character.
The nose was plugged both anteriorly and posteriorly, but the bleeding continued to a smaller extent the whole day.

On June 2 ist he was much worse, with continued vomiting. Both vomit and motions contained blood. The epistaxis continued the whole day in spite of everything that was done, but towards evening it abated, and finally ceased during the night. The jaundice was intense. The urine contained a large amount of albumen. There was great tenderness over the spleen. The abdomen was not distended. The temperature was quite normal, but his respirations were quicker, there being a good deal of congestion about the bases of the lungs.

On June 22nd he seemed a little better, and said he felt so, but towards night he commenced to ramble, and a man had to sit with him the whole night through, as he wanted to get out of the window, and had several times to be restrained.

He was quite sensible on June $23 \mathrm{rd}$, but was getting perceptibly weaker. I saw him four times that day, the last time in consultation with Dr. Horne, of Barnsles, who concurred in the diagnosis. The patient sank rapidly, and in the afternoon be was speaking to his brother when he suddenly fell back dead. He was quite sensible up to the end. I tried hard to get the relations to allow me to have a small piece of the liver in order to have it examined microscopically, but all my attempts were unavailing. I may add that whatever treatment was resorted to was entirely useless, the case gradually progressing to a fatal termination.

\section{A CASE OF ACUTE YELLOW ATROPHY OF THE LIVER.}

By C. T. ANDERSON, M.R.C.S., L R.C.P.,

Resident Medical Officer, Somerset Hospital, Capetown, South Africa.

THIs is the first case of acute yellow atropby which bas occurred in Somerset Hospital, and, as far as I can ascertain, in Capetown. The case was by no means typical, and the diagnosis was only arrived at four days before death.

A. E. M., aged 22, was one of the senior nurses at Somerset Hospital She was a talr, healthy, active girl, and had never been ill before. She was supposed to have had some mental worry, Lut it was not serious. Hev character was irreproachable.

\section{History of Illness.}

She returned to the hospital from her annual holiday in the early part of Januarr. 1808 . looking as well as usual, but told another nurse that she had slightly hurt her side some days previously, how or to what extent was never discovered. A week later, on January $13^{\text {th }}$, she was noticed II) be quieter than usual, and complained of a headache, but she continued on duty without saying anything more about it. On January r6th she took a pil. col. et hyosc., which acted on the follewing day, but later in the day she complained of indigestion. On January isth she was worse and was sent to bed. In the evening she complained of a constant feeling of sickness. with but little vomiting; bismuth and morphine gave no relief. On January sgth, besides the constant retching, she complained of great pain and tenderness all over the abdomen, which was very rigid. On January 20 th she was distinctly worse; the vomiting 作 astrium. On percussion it was noticed that there was a marked diminution in the area of liver dulness. After two days constipation. castor oil and several enemata proved all but ineffectual. A vaginai examination cast no light on the subject, although perimetritis was suspected at this stage. The urine on this day became slightly bile stained, and in the evening the patient became mildly delirious. Morphine was. njected, but it caused little relief. On January 23 rd the urine was found o be very dark indeed, almost black, and it continued very dark to the end. It was found to contain the bile pigment, and salts and a great. number of leucin plates, but no albumen, blood, or pus. The specific gravity was ro28.

The patient continued in much the same condition for the next two days, the chief trouble being the constipation. On January 24 th a double: oil and soap enema was followed by a large normal stool, and very soon after the patient seemed much better and brighter, the temperature which had never been high, fell to normal, the pulse was good, and the pain left her.

On January 26 th marked cerebral symptoms supervened. There was a feeling of weakness in both legs, which gradually increased to numbness and almost anæsthesia. On January 28 th the numbness had spread to the hands, and the patient began to wander in her speech. Tenderness was now quite limited to the area in front of the liver, and the area of liver dulness was still diminished, although not so markedly as a week previously. The diagnosis of acute yellow atrophy was now made. The cerebral symptoms became more marked and paralysis came on. The lucid intervals became skorter and her speech thicker. Her friends saw her on Monday, February ist, and were recognised, but she became comatose on Tuesday afternoon, and she died in the evening.

\section{Necropsy.}

Naked-eye Appearances. - The necropsy was made twenty hours after death. Verv little wasting was found, and there was no distension of the abdomen. The mesentery was very yellow, and the whole of the peri- 